\title{
A new approach for understanding ion transport in glasses; example of complex alkali diborate glasses containing lead, bismuth and tellurium oxides
}

\author{
V C VEERANNA GOWDA ${ }^{\dagger}$, C NARAYANA REDDY ${ }^{\ddagger}$ and K J RAO* \\ Solid State and Structural Chemistry Unit, Indian Institute of Science, Bangalore 560 012, India \\ ${ }^{\dagger}$ Department of Physics, Government College for Women, Chintamani 563 125, India \\ †Department of Physics, Maharani’s Science College for Women, Bangalore 560 001, India
}

MS received 14 November 2012

\begin{abstract}
Mechanism of ion transport in glasses continues to be incompletely understood. Several of the theoretical models in vogue fail to rationalize conductivity behaviour when d.c. and a.c. measurements are considered together. While they seem to involve the presence of at least two components in d.c. activation energy, experiments fail to reveal that feature. Further, only minor importance is given to the influence of structure of the glass on the ionic conductivity behaviour. In this paper, we have examined several general aspects of ion transport taking the example of ionically conducting glasses in pseudo binary, $y \mathrm{Na}_{2} \mathrm{~B}_{4} \mathrm{O}_{7} \cdot(1-y) \mathrm{M}_{a} \mathrm{O}_{b}$ (with $y=0 \cdot 25-0 \cdot 79$ and $\mathrm{M}_{a} \mathrm{O}_{b}=\mathrm{PbO}_{\text {, }}$ $\mathrm{TeO}_{2}$ and $\left.\mathrm{Bi}_{2} \mathrm{O}_{3}\right)$ system of glasses which have also been recently characterized. Ion transport in them has been studied in detail. We have proposed that non-bridging oxygen (NBO) participation is crucial to the understanding of the observed conductivity behaviour. NBO-BO switching is projected as the first important step in ion transport and alkali ion jump is a subsequent event with a characteristically lower barrier which is, therefore, not observed in any study. All important observations in d.c. and a.c. transport in glasses are found consistent with this model.
\end{abstract}

Keywords. Diborate glass; heavy metal ions; NBO-BO switching; lone pair electron.

\section{Introduction}

Ion transport in glasses has been studied for a very long time (Angell 1990; Funke 1993). In the absence of transition metal ions, conductivity in alkali modified glasses is generally attributed to the transport of alkali cations. It is a general practice to measure the impedances as a function of temperature and frequency (Elliott 1988; Sidebottom et al 2001; Roling et al 2001; Sundeep Kumar and Rao 2004a,b) and only occasionally under varying pressures (Angell et al 1965; Rao 1987, 2002; Imre et al 2006). Impedances are complex and from the Cole-Cole plot of these complex quantities, one extracts not only conductivities but limiting high and low frequency dielectric constants. The same a.c. conductivity data is often recast to obtain information on susceptibilities $\left(\chi^{\prime}\right.$ and $\left.\chi^{\prime \prime}\right)$ and dielectric moduli $\left(M^{\prime}\right.$ and $\left.M^{\prime \prime}\right)$ from which relaxation behaviour is examined.

From the enormous number of conductivity studies reported in the literature (Hughes and Isard 1972; Doremus 1973; Tomozawa 1977; Ravine and Souquet 1978; Rao and Parthasarathy 1985), only a few very general observations

\footnotetext{
*Author for correspondence (kalyajrao@yahoo.co.in)
}

have been noted (Dyre 1985, 1986; Dyre and Schroder 2000; Dyre et al 2009). Among them, two observations of relevance to this communication are (i) presence of d.c. electrical conductivity $\left(\sigma_{\mathrm{o}}\right)$ down to very low temperatures and (ii) the increase of a.c. conductivity at high frequencies as a power function of $\omega, \sigma(\omega) \sim \omega^{s}$, where ' $s$ ' is such that $0<s \leq 1 \cdot 0$. As a consequence, at high temperatures and high frequencies, most glasses have very similar conductivity. Curiously, the relaxation peak frequency, $\omega_{\mathrm{p}}$, obtained from a plot of the dielectric loss or the imaginary part of the moduli in a.c. measurements is found to be related to the frequency independent $\sigma_{\mathrm{o}}$ through the celebrated Barton-Nakajima-Namikawa (BNN) relation (Barton 1966; Nakajima 1972; Namikawa 1975) $\left(\sigma_{\mathrm{o}}=F \varepsilon_{\mathrm{o}} \Delta \varepsilon \omega_{\mathrm{p}}\right.$, where $\Delta \varepsilon$ is dielectric strength $\left(\varepsilon_{\mathrm{o}}-\varepsilon_{\infty}\right)$ and $F$ is a constant of the order of unity). This exceptionally valid empirical relation between d.c. and a.c. measurements appears to have deep implications for ionically conducting glasses viewed from the high frequency side at any given temperature; the relaxation frequency determines the values of d.c. conductivity, $\sigma_{\mathrm{o}}$, at a given temperature. The frequency of the electrical field becomes irrelevant to the value of $\sigma_{\mathrm{o}}$ below roughly half of $\omega_{\mathrm{p}}$. Even more interestingly, BNN correlation is independent of the glass composition (except in a minor way through $\Delta \varepsilon$ ). Many a discussion of ion transport in literature appears to attribute minor importance to 
the influence of structure of the glasses to their conductivity behaviour. We should like to examine this feature in some detail.

We have investigated a.c. conductivity and dielectric relaxation behaviour of sodium diborate glasses. Alkali diborates are a particular combination in the pseudo-binary alkali- $\mathrm{B}_{2} \mathrm{O}_{3}$ system of glasses (further) modified by the addition of heavy metal oxides, $\mathrm{PbO}, \mathrm{Bi}_{2} \mathrm{O}_{3}$ and $\mathrm{TeO}_{2}$. Diborate ions generally tend to be present as tightly bound bicyclic units consisting of two trigonally and two tetrahedrally bonded boron atoms in alternate positions of the ring. The two negative charges on the diborate unit are delocalized on the whole structure. The unit behaves like a tetra coordinated single entity. But structure of the diborate unit can be disrupted to certain extent by adding $\mathrm{PbO}$ (Veeranna Gowda et al 2007). The disruption is, however, much less when $\mathrm{TeO}_{2}$ is added. The diborate structure is essentially unaffected by $\mathrm{Bi}_{2} \mathrm{O}_{3}$. In the case of $\mathrm{PbO}$ also, diborate unit is stable against disruption when $\mathrm{PbO}$ concentration is lower than $\sim 30 \%$ in the pseudo-binary $\mathrm{Na}_{2} \mathrm{~B}_{4} \mathrm{O}_{7}-\mathrm{PbO}$ glasses.

The modifiers used here viz. $\mathrm{PbO}, \mathrm{Bi}_{2} \mathrm{O}_{3}$ and $\mathrm{TeO}_{2}$ contain lone pair bearing ions, $\mathrm{Pb}^{2+}, \mathrm{Bi}^{3+}$ and $\mathrm{Te}^{4+}$. We have in our earlier studies (Veeranna Gowda et al 2007) obtained spectroscopic (MAS NMR) evidence to show that the $B_{4} / B_{3}$ ratio remains unaltered and near unity in all glass compositions. We have also shown that the tightly bound diborate units only open up into larger rings or chains in order to provide additional oxygen coordination required by $\mathrm{Pb}^{2+}$ in high $\mathrm{PbO}$ glasses. Lead atoms have been found to prefer four coordinated network positions when $\mathrm{PbO}$ concentration is high. $\mathrm{TeO}_{2}$ appears to make a sub-network in $\mathrm{Na}_{2} \mathrm{~B}_{4} \mathrm{O}_{7}-$ $\mathrm{TeO}_{2}$ glasses and it is present in both trigonal bypyramidal (tbp), and trigonal pyramidal (tp), configurations (Rao and Harish Bhat 2001). $\mathrm{TeO}_{2}$ network appears to permeate the extensive diborate network. $\mathrm{Bi}_{2} \mathrm{O}_{3}$ seems to form $\mathrm{BiO}_{3 / 2}$ networks which integrate into the diborate network in such a way that bismuth occupies six coordinated position utilizing oxygen atoms of the borate network (Veeranna Gowda et al 2007).

Our attention here is focused on understanding how ion transport takes place in such a matrix and still exhibit the earlier mentioned general features of ion transport. There are two special features of these glasses and they are (i) the negative charges on diborate units are diffuse and (ii) the cations $(\mathrm{Pb}, \mathrm{Bi}$ and $\mathrm{Te})$ carry lone pair electrons. It is well known that these lone pairs are stereochemically active (Galy and Meunier 1975). We should like to examine how the measured transport parameters help us to understand ion transport mechanisms.

In the next section, we describe the experimental studies conducted in these glasses over wide frequency and temperature ranges and the manner of acquisition and analysis of the data. In the subsequent 'results and discussion' section, we analyse our observation using several currently popular models of ion transport in glasses and show that it is very likely that in these oxide glasses the non-bridging oxygens (NBOs) play a significant role in ion transport. We also examine several general aspects of ion transport discussed in the literature from the perspective of dominant NBO participation.

\section{Experimental}

Three glass systems have been prepared with the pseudobinary compositions, $y \mathrm{Na}_{2} \mathrm{~B}_{4} \mathrm{O}_{7} \cdot(1-y) \mathrm{M}_{a} \mathrm{O}_{b}$ and $y$ has been varied from 0.25 to 0.79 . These glasses are actually ternaries of composition, $x \mathrm{Na}_{2} \mathrm{O} \cdot 2 x \mathrm{~B}_{2} \mathrm{O}_{3} \cdot(1-3 x) \mathrm{M}_{a} \mathrm{O}_{b}$ and the equivalence in composition requires $y=3 x$ so that the ternary glass composition expressed through $y$ is $(y / 3) \mathrm{Na}_{2} \mathrm{O} \cdot(2 y / 3) \mathrm{B}_{2} \mathrm{O}_{3} \cdot(1-y) \mathrm{M}_{a} \mathrm{O}_{b}$. The series of glasses have been designated as pseudo-binary NBP (sodium diborate-lead oxide), NBT (sodium diboratetellurium oxide) and NBB (sodium diborate-bismuth oxide) glasses, respectively. Reagent grade $\mathrm{H}_{3} \mathrm{BO}_{3}, \mathrm{TeO}_{2}, \mathrm{Bi}_{2} \mathrm{O}_{3}$, $\mathrm{PbO}$ and $\mathrm{Na}_{2} \mathrm{CO}_{3} \cdot \mathrm{H}_{2} \mathrm{O}$ were used as the starting materials. The starting materials were weighed in required proportions and the components were thoroughly mixed by grinding together and were heated in ceramic crucibles at $450{ }^{\circ} \mathrm{C}$ for $30 \mathrm{~min}$ to get rid of water. During heating, $\mathrm{CO}_{2}$ gets removed through decomposition. The batches melt between $900{ }^{\circ} \mathrm{C}$ and $1200{ }^{\circ} \mathrm{C}$ depending on the composition. The glass samples were obtained by quenching the melt between brass blocks pre-heated $\left(\approx 120{ }^{\circ} \mathrm{C}\right)$ which prevents cracking of the samples due to thermal strains. Later, the samples were annealed by holding them just below their glass transition temperatures for $6 \mathrm{~h}$ and slowly cooling them to laboratory temperature. Samples were polished under dry condition using silicon carbide powder (nos 320 and 400 Carborundum, Manchester-17, UK) to obtain flat parallel surfaces. Such sample geometries are suitable for electrical conductivity measurements.

$0 \cdot 21 \mathrm{Na}_{2} \mathrm{~B}_{4} \mathrm{O}_{7} \cdot 0 \cdot 79 \mathrm{PbO} / \mathrm{Bi}_{2} \mathrm{O}_{3}$ glasses were slightly yellowish in colour. Glasses were quite stable in air and did not exhibit any hygroscopicity. However, slight loss of $\mathrm{PbO}$ and $\mathrm{Bi}_{2} \mathrm{O}_{3}$ during homogenization of the melt at $1000-1200{ }^{\circ} \mathrm{C}$ for a few min could not be ruled out. The composition given in table 1 refers to the nominal composition of the starting mixtures.

Electrical conductivity measurements were carried out on a Hewlett Packard HP 4192A impedance gain phase analyser from $100 \mathrm{~Hz}$ to $10 \mathrm{MHz}$ in the temperature range 298-523 K. A home built cell assembly (2-terminal capacitor configuration and spring loaded silver electrodes) were used in all measurements. The sample temperature was measured using a Pt-Rh thermocouple positioned very close to the sample. The temperature was controlled using a Heatcon (Bangalore, India) temperature controller and the temperature constancy of $\pm 1 \mathrm{~K}$ was achieved in the entire range of measurements. Annealed circular glass pieces, coated with silver paint on both sides and having a thickness of about $0.1 \mathrm{~cm}$ and a diameter of $1 \mathrm{~cm}$ were used for the measurements. 
Table 1. The code, composition, $\sigma_{\mathrm{dc}}, s$ and $\beta$ (at $275^{\circ} \mathrm{C}$ ) and $E_{\mathrm{dc}}$.

\begin{tabular}{|c|c|c|c|c|c|c|c|}
\hline \multirow[t]{2}{*}{ Code } & \multicolumn{2}{|c|}{ Composition (mol\%) } & \multirow[t]{2}{*}{$\begin{array}{l}\sigma_{\mathrm{dc}} \mathrm{Scm}^{-1} \\
\text { (at } 275^{\circ} \mathrm{C} \text { ) }\end{array}$} & \multirow[t]{2}{*}{$s$} & \multirow[t]{2}{*}{$\beta$} & \multirow[t]{2}{*}{$\begin{array}{c}E_{\mathrm{dc}} \\
(\mathrm{eV})\end{array}$} & \multirow[t]{2}{*}{$\begin{array}{l}T_{\mathrm{g}}^{*} \\
(\mathrm{~K})\end{array}$} \\
\hline & $\mathrm{Na}_{2} \mathrm{~B}_{4} \mathrm{O}_{7}$ & $\mathrm{PbO}$ & & & & & \\
\hline NBP1 & 75 & 25 & $1.55 \times 10^{-7}$ & $0 \cdot 65$ & - & $1 \cdot 15$ & 618 \\
\hline NBP2 & 50 & 50 & $1.78 \times 10^{-8}$ & 0.53 & $0 \cdot 92$ & $1 \cdot 20$ & 613 \\
\hline NBP3 & 33 & 67 & - & 0.54 & $0 \cdot 96$ & $1 \cdot 26$ & 597 \\
\hline \multirow[t]{2}{*}{ NBP4 } & 21 & 79 & - & - & - & - & 577 \\
\hline & $\mathrm{Na}_{2} \mathrm{~B}_{4} \mathrm{O}_{7}$ & $\mathrm{TeO}_{2}$ & & & & & \\
\hline NBT1 & 75 & 25 & $2.63 \times 10^{-6}$ & 0.49 & 0.92 & 0.91 & 685 \\
\hline NBT2 & 50 & 50 & $2.06 \times 10^{-7}$ & 0.52 & 0.78 & 1.06 & 646 \\
\hline NBT3 & 33 & 67 & $1.16 \times 10^{-8}$ & 0.47 & $0 \cdot 91$ & $1 \cdot 10$ & 616 \\
\hline \multirow[t]{2}{*}{ NBT4 } & 21 & 79 & $8.31 \times 10^{-10}$ & 0.53 & - & $1 \cdot 12$ & 591 \\
\hline & $\mathrm{Na}_{2} \mathrm{~B}_{4} \mathrm{O}_{7}$ & $\mathrm{Bi}_{2} \mathrm{O}_{3}$ & & & & & \\
\hline NBB1 & 75 & 25 & $6.79 \times 10^{-7}$ & 0.55 & 0.92 & 0.96 & 665 \\
\hline NBB2 & 50 & 50 & $3.02 \times 10^{-8}$ & 0.56 & $0 \cdot 81$ & 0.94 & 650 \\
\hline NBB3 & 33 & 67 & $1.83 \times 10^{-9}$ & 0.57 & - & 1.02 & 636 \\
\hline NBB4 & 21 & 79 & $6.52 \times 10^{-9}$ & 0.73 & - & 0.98 & 612 \\
\hline
\end{tabular}

${ }^{*}$ Reported in our earlier studies (Veeranna Gowda et al 2007)

\section{Analysis of data}

The capacitance $\left(C_{\mathrm{p}}\right)$ and conductance $(G)$ of all the samples were measured from the impedance analyser. These were used to evaluate real and imaginary parts of the complex impedance using standard relations (Macdonald 1983; Sundeep Kumar and Rao 2004b),

$$
\begin{aligned}
& Z^{*}=Z^{\prime}+j Z^{\prime \prime}=\frac{1}{\left(G+j \omega C_{\mathrm{p}}\right)}, \\
& Z^{\prime}=\frac{G}{\left(G^{2}+\omega^{2} C_{\mathrm{p}}^{2}\right)}, \\
& Z^{\prime \prime}=\frac{\omega G_{\mathrm{p}}}{\left(G^{2}+\omega^{2} C_{\mathrm{p}}^{2}\right)} .
\end{aligned}
$$

The d.c. conductances were determined from the semicircular complex impedance ( $Z^{\prime}$ vs $\left.Z^{\prime \prime}\right)$ plots by taking the value of intersection of the low frequency end of the semicircle on $Z^{\prime}$ axis. The conductivity $(\sigma)$ for each sample was calculated using the expression

$$
\sigma=G\left(\frac{d}{A}\right)
$$

where $d$ and $A$ are the thickness and area of the sample, respectively.

The real $\left(\varepsilon^{\prime}\right)$ and imaginary $\left(\varepsilon^{\prime \prime}\right)$ parts of the complex dielectric constant were calculated using the relations,

$$
\varepsilon^{\prime}=\frac{C_{\mathrm{p}} d}{A \varepsilon_{0}},
$$

$$
\varepsilon^{\prime \prime}=\frac{\sigma}{\varepsilon_{0} \omega},
$$

where $\varepsilon_{0}$ is the permittivity of the free space which has a value of $8.854 \times 10^{-14} \mathrm{~F} \mathrm{~cm}^{-1}$.

The data were also analysed using the electrical modulus formalism (Macedo et al 1972). The real $\left(M^{\prime}\right)$ and imaginary $\left(M^{\prime \prime}\right)$ parts of the complex electrical modulus $\left(M^{*}=1 / \varepsilon^{*}\right)$ were obtained from $\varepsilon^{\prime}$ and $\varepsilon^{\prime \prime}$ values using the relations,

$$
\begin{aligned}
& M^{\prime}=\frac{\varepsilon^{\prime}}{\left(\varepsilon^{\prime 2}+\varepsilon^{\prime \prime 2}\right)}, \\
& M^{\prime \prime}=\frac{\varepsilon^{\prime \prime}}{\left(\varepsilon^{\prime 2}+\varepsilon^{\prime \prime 2}\right)} .
\end{aligned}
$$

\section{Results and discussion}

The compositions of the glasses investigated and their codes are presented in table 1 . In the binaries, concentrations of lead, tellurium and bismuth have been systematically increased from 25 to $79 \%$. It is interesting to note at the outset that up to 80 mole\% lone pair metal oxides (LPM) can be stuffed into sodium diborate without losing glass forming ability.

\subsection{D.C. conductivity}

Cole-Cole plots at four different temperatures for the $\mathrm{TeO}_{2}$ containing NBT1 glass is presented in figure 1. This is typical 


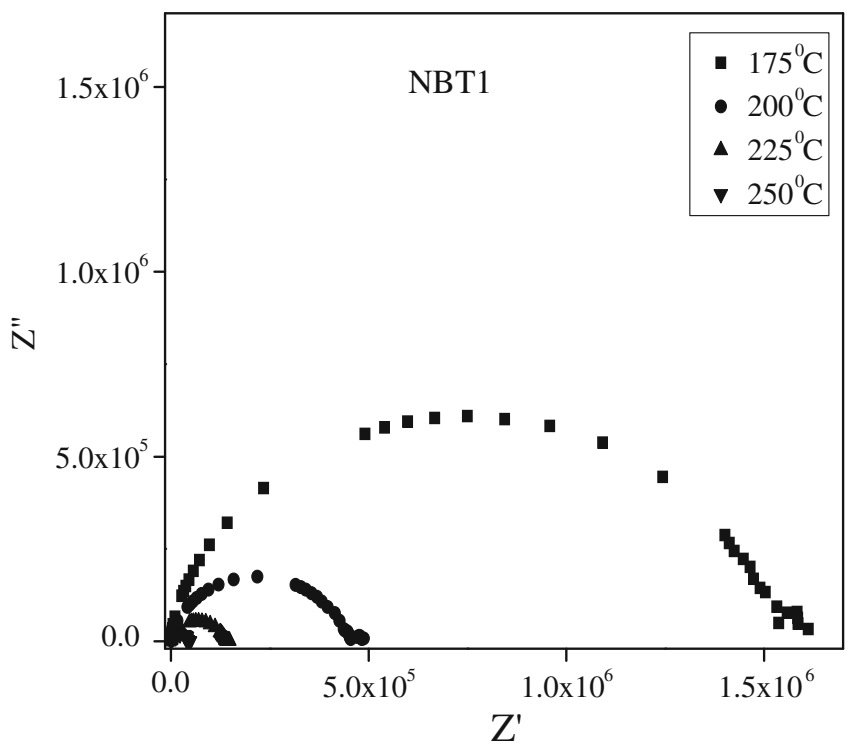

Figure 1. Cole-Cole plot for NBT1 glass at different temperatures. of all the glasses investigated here. The semi-circles of the impedance plot, $Z^{\prime \prime}$ vs $Z^{\prime}$, measured over a frequency range $100 \mathrm{~Hz}$ to $10 \mathrm{MHz}$ yield points of intersection on the real axis (corresponding to 0 or $\infty$ frequency values of impedance). Along with the geometry of the samples, it enables evaluation of resistivities. D.C. conductivities have been calculated using the resistivity values from the intersection point at $\omega=0$. In figures 2 (a), (b) and (c), Arrhenius plots of the measured conductivities are shown for all the three systems and the activation barriers calculated from the slopes are given in table 1 . The variation of the conductivity as a function of concentration of LPM oxide is shown in figures $3 \mathrm{a}$ and $b$, the variation is nearly linear at any given temperature for NBP and NBT glasses. Only in the case of NBB glasses, the conductivity begins to increase above $70 \mathrm{~mol} \%$ of $\mathrm{Bi}_{2} \mathrm{O}_{3}$ (figure 3c). The entire d.c. conductivity behaviour appears to be consistent with a structural model of these glasses proposed by us earlier (Muthupari et al 1996). As pointed out earlier the principal feature of this model is that the glass structure is made up of tightly bound diborate units. The conductivity is, therefore, determined by influence of the
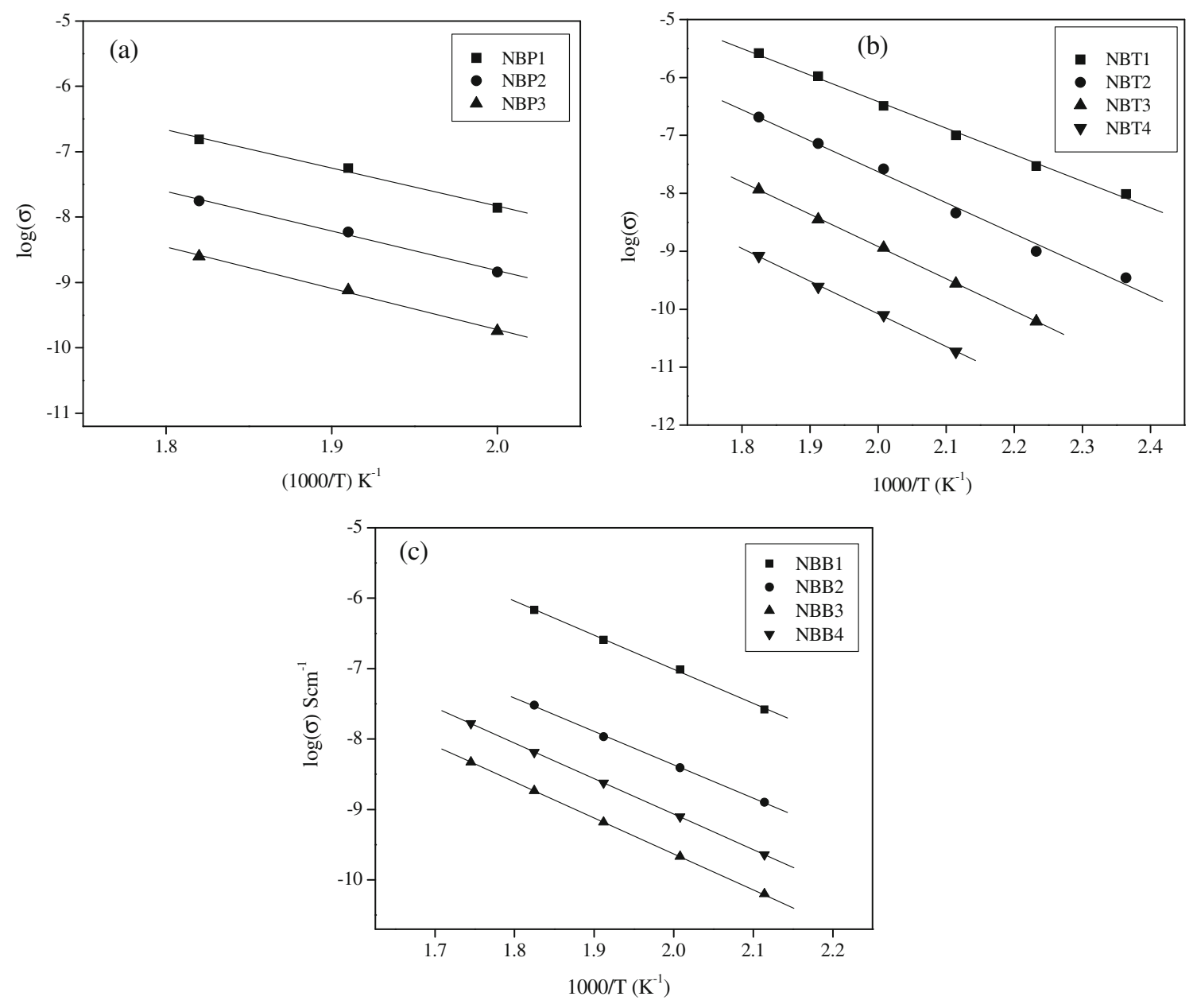

Figure 2. Variation of $\log \left(\sigma_{\mathrm{dc}}\right)$ vs $1000 / T$ for (a) NBP, (b) NBT and (c) NBB glasses. 
size of diborate ion as long as the structural integrity of the diborate units is preserved. Diborate units are large ions with diffuse negative charge and with four covalent bonding (to other entities) points as shown below (Veeranna Gowda et al 2007).

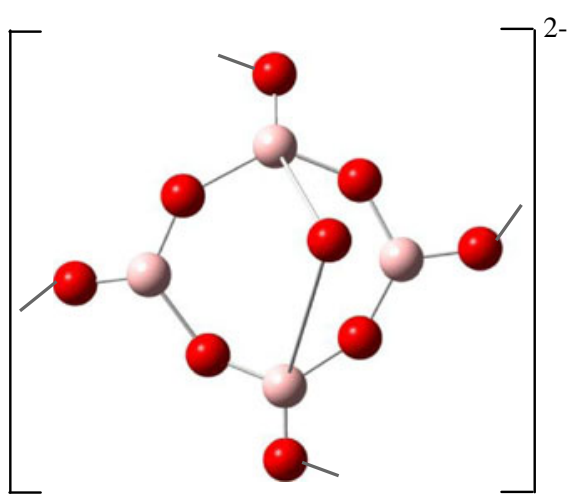

8
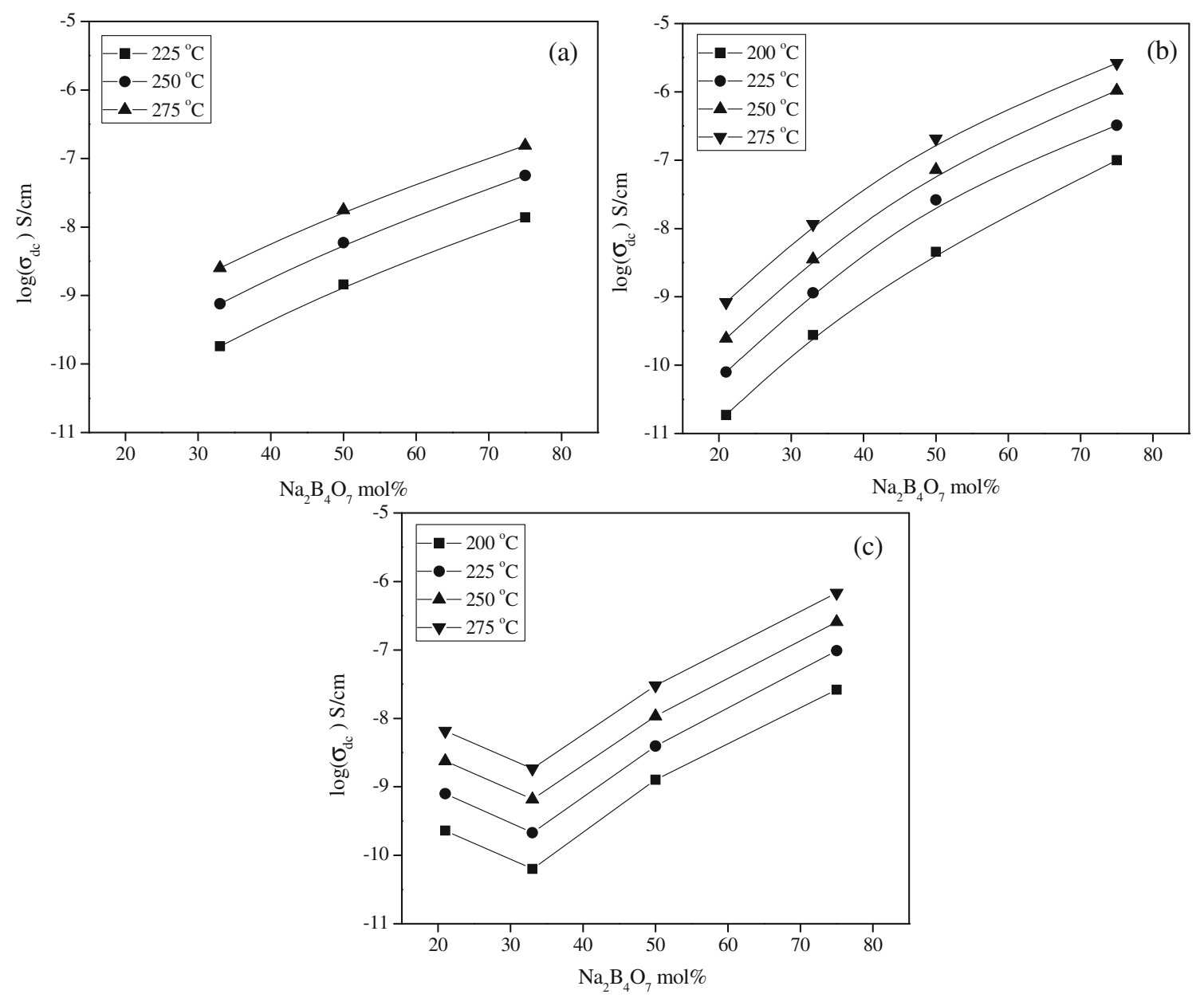

Figure 3. Variation of $\log (\sigma)$ vs $\mathrm{Na}_{2} \mathrm{~B}_{4} \mathrm{O}_{7}$ mol\% for (a) NBP, (b) NBT and (c) NBB glasses.
When other oxides are added to a pure diborate glass and if they do not interfere with the basic diborate glass structure, the structure gets expanded resulting in larger voids. This leads to lowering of activation barriers and enhancement of conductivities. But added lead oxide disturbs diborate glass structure. It breaks open the tight diborate unit and in the process leads to denser packing of the components of the glass structure. $\mathrm{Pb}$ atoms themselves have a tendency to form four coordinated $\left[\mathrm{PbO}_{2 / 2} \mathrm{O}_{2}\right]^{2-}$. These $\left[\mathrm{PbO}_{2 / 2} \mathrm{O}_{2}\right]^{2-}$ units are covalently bonded and integrated into the structure. The resulting dense packing along with the presence of stereochemically active (SCA) lone pair reduces the mobility of charge carriers. Lone pairs produce an electrical drag on positively charged mobile cations like $\mathrm{Na}^{+}$. Therefore, addition of $\mathrm{PbO}$ has two effects both of which increase in the same direction with its concentration in diborate glass and both tend to reduce conductivity. This is consistent with $\sigma_{\mathrm{dc}}$ variation with $\mathrm{PbO}$ concentration as shown in figure $3 \mathrm{a}$.

Similar but not identical situation occurs with $\mathrm{TeO}_{2}$ addition to NBT glasses. $\mathrm{TeO}_{2}$ forms connected tbp units (see below) permeating diborate network in the glass. 


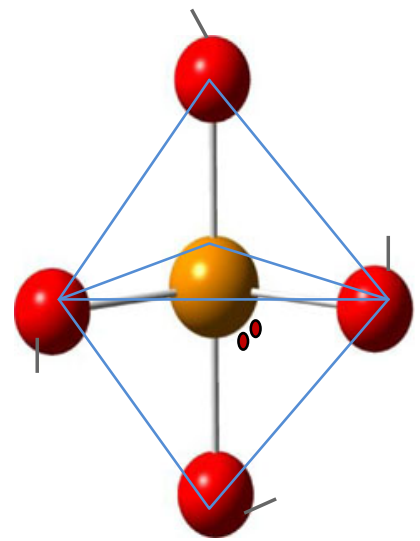

Trigonal bipyramidal (tbp)

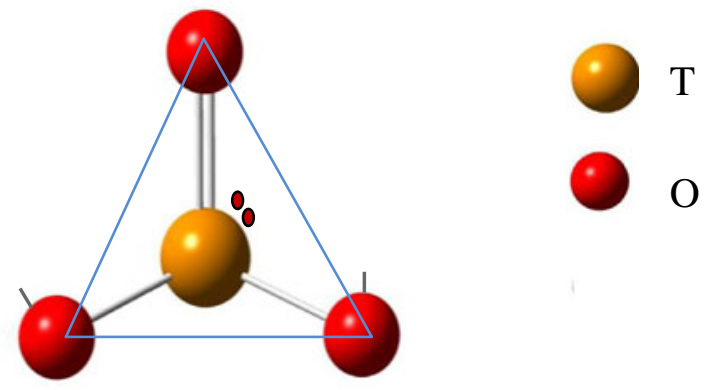

Trigonal pyramidal (tp)
As the concentration of $\mathrm{TeO}_{2}$ increases the molar volume of glass decreases as a function of $\mathrm{TeO}_{2}$ concentration for reasons of better space filling compared to pure diborate glass structure. There is good spectroscopic evidence (Veeranna Gowda et al 2007) to believe that $\mathrm{TeO}_{2}$ interacts very little with diborate network. The lone pair on tellurium has the same dragging (mobility hindering) effect on alkali ions. Therefore, the conductivity behaviour observed in NBT glasses in figure $3 \mathrm{~b}$ is quite as expected. In NBB glasses with $\mathrm{Bi}_{2} \mathrm{O}_{3}$ concentration of $>70 \mathrm{~mol} \%$, the conductivity varies anomalously. This is likely to be due to slightly enhanced mobilities associated with bond switching efficiency and will be discussed later.

\subsection{Alkali ion transport models}

The present understanding of the mechanism of d.c. conduction suffers from serious conceptual deficiencies (Rao et al 1993). The earliest modeling of conductivity was by Anderson and Stuart (A-S). This is essentially a strong electrolyte model (Anderson and Stuart 1954). It considers the alkali oxide to have reacted completely with the network former creating non-bridging oxygens and free alkali ions. The model treats all alkali ions as effective charge carriers. The motion of alkali ions occurs in a medium of randomly distributed but positionally fixed non-bridging oxygens (NBOs) of same concentration as alkali ions. Alkali ions reside close to NBOs. The migration of alkali ion requires two equivalent positions near two distinct NBOs. As the alkali ion moves from one to the other equivalent position, it overcomes a coulombic barrier and also a mechanical barrier since it has to move through a 'bottle neck' created by oxygens. The bottle neck position generally (but not necessarily) consists of three oxygen atoms touching each other. Thus A-S theory considers that activation barrier, $E_{\mathrm{a}}=E_{\mathrm{c}}+E_{\mathrm{s}}$ (where $E_{\mathrm{c}}$ is the columbic barrier and $E_{\mathrm{s}}$ the strain energy barrier which arises from the mechanical hindrance). Ravine and Souquet (1977) did not consider all alkali ions as candidates for conduction. They considered alkali oxides as partially ionized like $\mathrm{Na}_{2} \mathrm{O} \rightleftharpoons \mathrm{Na}^{+}+\mathrm{NaO}^{-}$ providing an equilibrium concentration of $\mathrm{Na}^{+}$ions which are considered as mobile. The generation of these ions requires an energy expenditure equal to $\Delta H / 2$, where $\Delta H$ is the enthalpy of the above reaction. $\mathrm{Na}^{+}$, however, would require to overcome the mechanical barrier, $E_{\mathrm{m}}$ (same as $E_{\mathrm{s}}$ of A-S model). Therefore, in the weak electrolyte theory of $\mathrm{R}-\mathrm{S}, E_{\mathrm{a}}=\Delta H / 2+E_{\mathrm{m}}$.

Thus in the analysis of the conductivities, $E_{\mathrm{a}}$ has been generally treated as constituted of two components in these theories. This feature was emphasized in a later analysis by Martin and Angell (see their barrier cartoon in the reference Martin and Angell 1986). However, in the analysis of Martin and Angell, there appears to be a conceptual leaning towards $\mathrm{R}-\mathrm{S}$ approach, because, the columbic and mechanical barriers are not merged and the process of activation appears to involve a metastable state for it to build up a finite concentration of candidate ions which later undergo migration. But none of the reported experiments reveals the presence of two or two-stage barrier. All conductivity measurements reported so far reveal the presence of only a single characteristic migration barrier. This single barrier feature is observed even in mixed alkali glasses (Harish Bhat et al 2004a,b).

The statistics of conductivity data available on activation barriers is interesting. We have collected in figures 4 $\mathrm{a}, \mathrm{b}, \mathrm{c}$ and $\mathrm{d}$, measured activation barriers in four different categories of glasses, phosphates, borates, silicates and other oxide glass systems particularly those containing $\mathrm{PbO}$, $\mathrm{TeO}_{2}$ and $\mathrm{Bi}_{2} \mathrm{O}_{3}$ (and their combinations) (Mazurin and Borisovskii 1957; Isard 1959; Charles 1966; Terai 1969; Hakim and Uhlmann 1971; Bartholomew 1973; Ravaine et al 1975; Han et al 1979; Hunter and Ingram 1984; Ravine 1985; Martin and Angell 1986; De Marchi et al 1988; Gandhi et al 1989; Chen et al 1992; Chryssikos et al 1998; Souquet et al 1998; Pan and Ghosh 1999a, b; Altaf et al 2001; Gao and Cramer 2005; Veeranna Gowda and Anavekar 2005; Murugaraj 2007; Al-Assiri et al 2008). The $x$-axis has been chosen to represent the mole fraction of the so called network 

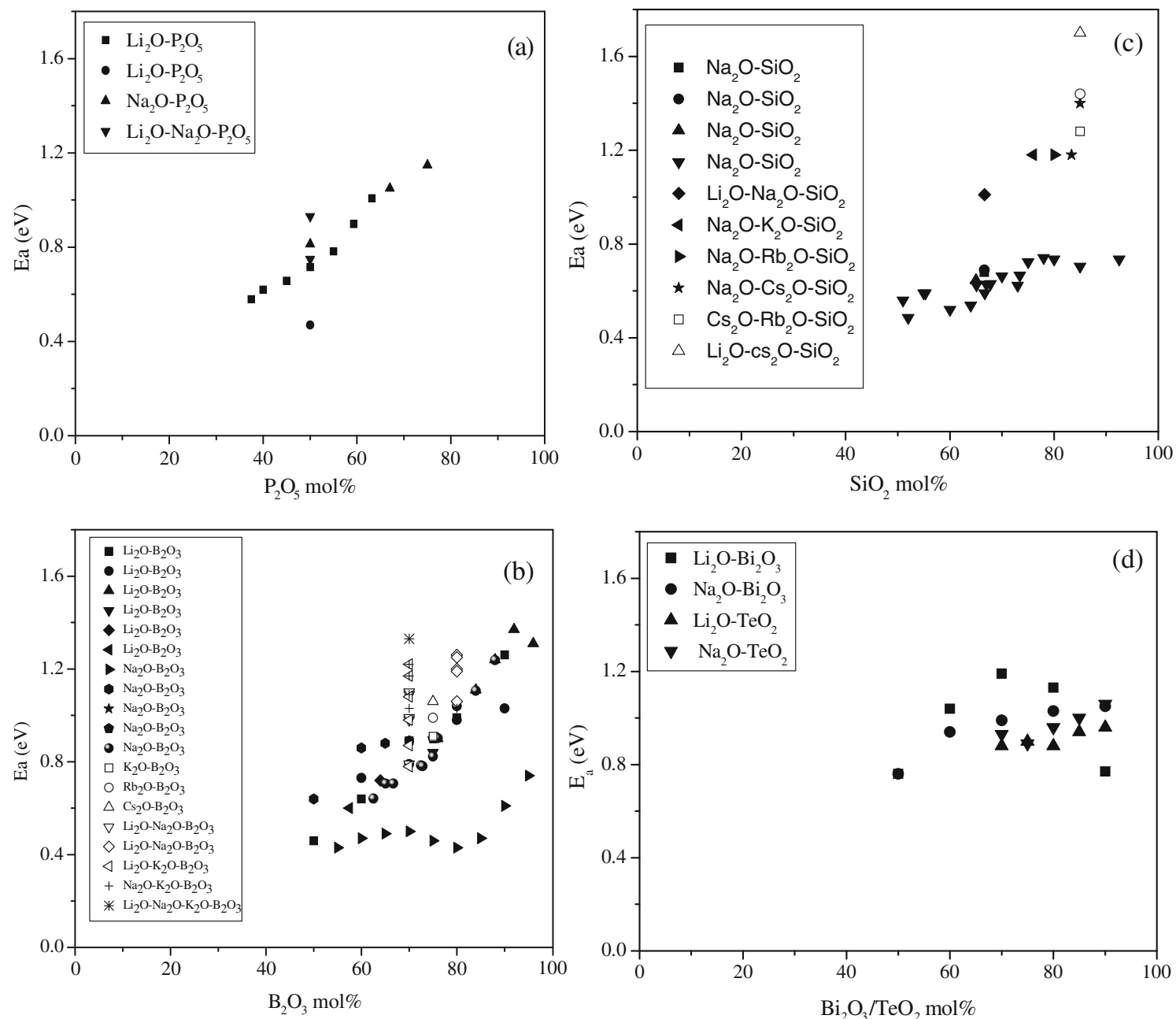

Figure 4. Variation of activation energy $\left(E_{\mathrm{dc}}\right)$ vs (a) $\mathrm{P}_{2} \mathrm{O}_{5}$ (Bartholomew 1973; Martin and Angell 1986; Chen et al 1992; Altaf et al 2001), (b) $\mathrm{B}_{2} \mathrm{O}_{3}$ mol\% (Han et al 1979; Hunter and Ingram 1984; Ravine 1985; Gandhi et al 1989; Chryssikos et al 1998; Gao and Cramer 2005; Veeranna Gowda and Anavekar 2005; Murugaraj 2007; Al-Assiri et al 2008), (c) $\mathrm{SiO}_{2}$ (Mazurin and Borisovskii 1957; Isard 1959; Charles 1966; Terai 1969; Hakim and Uhlmann 1971; Ravaine et al 1975; De Marchi et al 1988; Souquet et al 1998) and (d) $\mathrm{Bi}_{2} \mathrm{O}_{3} / \mathrm{TeO}_{2}$ mol\% (Pan and Ghosh 1999a,b; Murugaraj 2007).

former $\left(\mathrm{P}_{2} \mathrm{O}_{5}, \mathrm{~B}_{2} \mathrm{O}_{3}, \mathrm{SiO}_{2}\right.$ or $\left.\mathrm{TeO}_{2}\right)$ in glasses. The figures reveal bewildering spread of activation barriers revealing no significant trend attributable to the size of the alkali ion or any other physical property of the cations. Activation barrier histograms (number of systems having barriers between $\left(E_{\mathrm{a}}+\Delta E_{\mathrm{a}}\right)$, not shown as a figure) suggest that the spread of activation barriers do decrease but not enough to suggest operation of any unique transport mechanism.

D.C. activation barriers observed in presently investigated glasses are among the higher values of barriers observed in diborate glasses. These activation barriers are plotted as a function of sodium diborate concentration in figure 5. Upon reasonable extrapolation, the observed values appear close to the observed experimental $E_{\mathrm{a}}$ value for pure sodium diborate glass (Muthupari et al 1996) inspite of the differences in the structural effects brought about by $\mathrm{PbO}, \mathrm{TeO}_{2}$ and $\mathrm{Bi}_{2} \mathrm{O}_{3}$. As noted earlier, the pseudo-binary $(1-y)\left(\mathrm{Na}_{2} \mathrm{~B}_{4} \mathrm{O}_{7}\right)$ and $y\left(\mathrm{M}_{a} \mathrm{O}_{b}\right)$ glass structure is primarily based on exten-

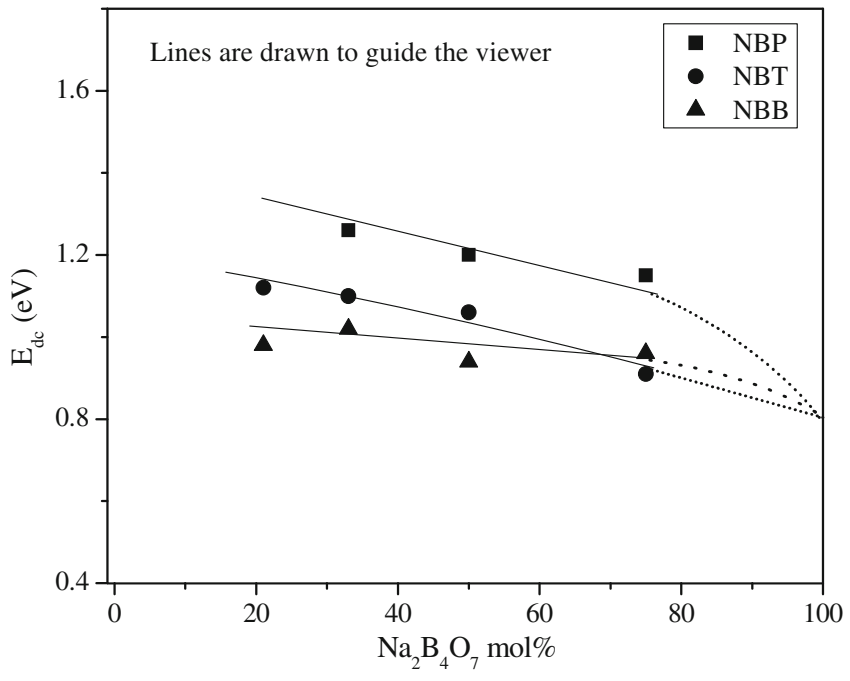

Figure 5. Variation of activation energy $\left(E_{\mathrm{dc}}\right) \mathrm{vs} \mathrm{Na}_{2} \mathrm{~B}_{4} \mathrm{O}_{7} \mathrm{~mol} \%$. 
sive three dimensional network of diborate $\left[\mathrm{B}_{4} \mathrm{O}_{7}\right]^{2-}$ units. In such a structure one would expect sodium ion migration by hopping to be significantly affected by the second network forming element arising from $\mathrm{PbO}, \mathrm{TeO}_{2}$ or $\mathrm{Bi}_{2} \mathrm{O}_{3}$. But it is amazing that the activation barriers are in such a narrow range and within the experimental limits may be considered as $\approx 1 \mathrm{eV}$. There was also no indication of a two-stage (separable experimentally) barrier as implied in ion transport models. Nevertheless, we wish to add that in any such two barrier situations, if one of the barriers is dominant, the second is only a minor barrier and the latter may not be seen in conductivity experiments.

\subsection{Transport via NBO-BO switching mechanism}

We have proposed in earlier publications (Harish Bhat et al 2004a,b; Rao and Sundeep Kumar 2003; Sundeep Kumar and Rao 2004a,b; Sundeep Kumar et al 2004) that in modified oxide glasses, ion transport is likely to be initiated by NBO$\mathrm{BO}$ switching. NBO-BO switching can itself occur either through a transient over coordination of the network forming element, or through the exploitation of polycoordination capability of the network forming atom (scheme 1). In silicates, for example, NBO-BO switching can be systematically represented as
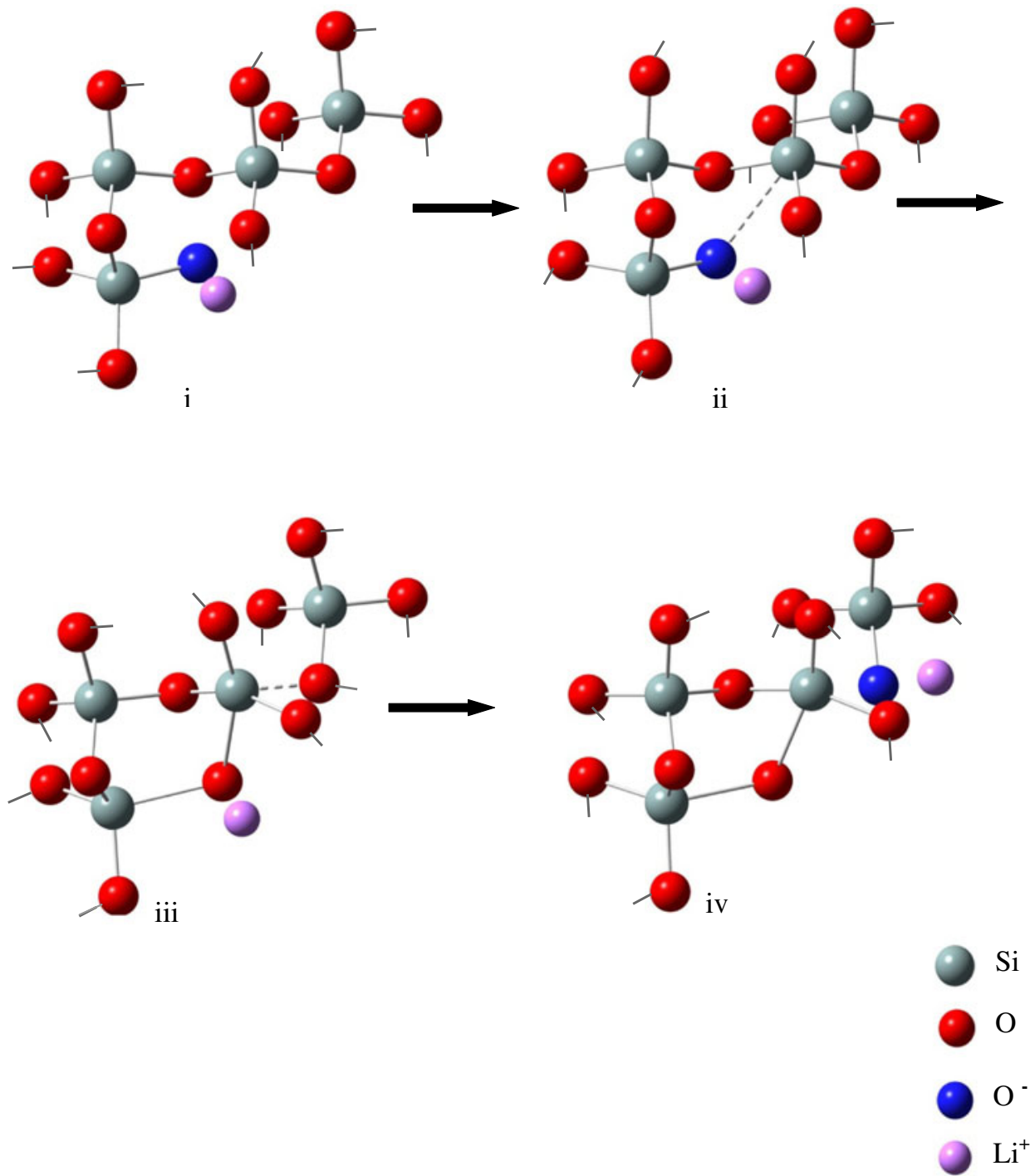

Scheme 1. $\mathrm{Si}_{3}-\mathrm{Si}_{4}-\mathrm{Si}_{4}-\mathrm{Si}_{4} \rightarrow \mathrm{Si}_{4}-\mathrm{Si}_{5}-\mathrm{Si}_{4}-\mathrm{Si}_{4} \rightarrow \mathrm{Si}_{4}-\mathrm{Si}_{4}-\mathrm{Si}_{3}-\mathrm{Si}_{4}$. 
In the case of borate glasses,
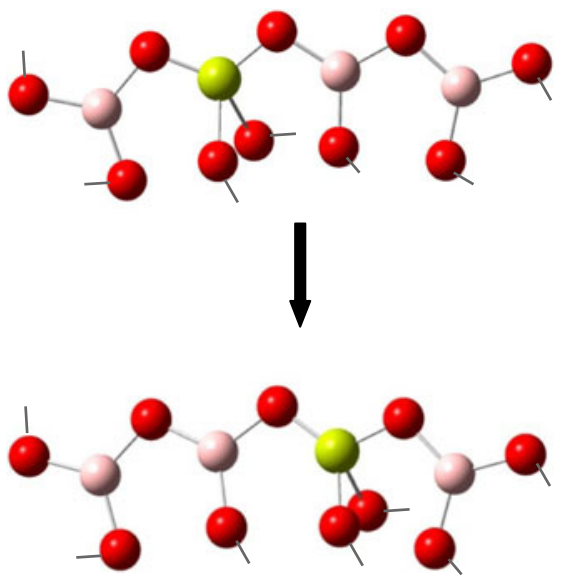

Scheme 2. $\mathrm{B}_{3}-\mathrm{B}_{4}-\mathrm{B}_{3}-\mathrm{B}_{3} \rightarrow \mathrm{B}_{3}-\mathrm{B}_{3}-\mathrm{B}_{4}-\mathrm{B}_{3}$.

In borate glasses it can occur by simple shifting of the charge through bond reorganization at the network forming centre as shown in scheme 2 above. In phosphate glasses, the NBO-BO switching may follow the same mechanism as in silicate glasses. The net energy change required to create these transient states constitutes the actual (measured) activation barriers. The process is NBO-BO switching and it involves only moving of the negative charge and not the oxide ion. There is no associated mass transport. NBO-BO bond switching has an interesting and vital consequence. It destabilizes the alkali ion in its position because it was situated close to a NBO which has migrated in the process of BO-NBO switching (The position where alkali ions are situated in glass is in reality a 'pseudo equilibrium' position and does not necessarily represent the lowest energy position). Therefore, cation now moves to new position where it is again situated close to an NBO. This is the mass transport event. This step, we assume, involves overcoming a lower energy barrier and also dependent on the anion matrix. Therefore, in glasses it is the NBO switching step which is large and determines the activation energy. This is the reason why it is essentially constant for glasses of a particular class (phosphates, borates etc) and virtually independent of the cation.

The magnitude of the electrical conductivities in the present system of glasses also become primarily a function of diborate concentration, which determines the concentration of mobile ions. Since $T_{\mathrm{g}}$ 's of these glasses are also similar (table 1), the observed conductivities at $275^{\circ} \mathrm{C}$ given in table 1 are very similar for all the glasses when the concentration of $\mathrm{Na}_{2} \mathrm{~B}_{4} \mathrm{O}_{7}$ is the same (conductivities are to be strictly compared at temperatures scaled with reference to $T_{\mathrm{g}}$ ).

In figure 3, however, we notice a change in the trends of conductivity close to $70 \mathrm{~mol} \%$ of $\mathrm{Bi}_{2} \mathrm{O}_{3}$ in NBB glasses. This change of trend at high $\mathrm{Bi}_{2} \mathrm{O}_{3}$ concentration is also

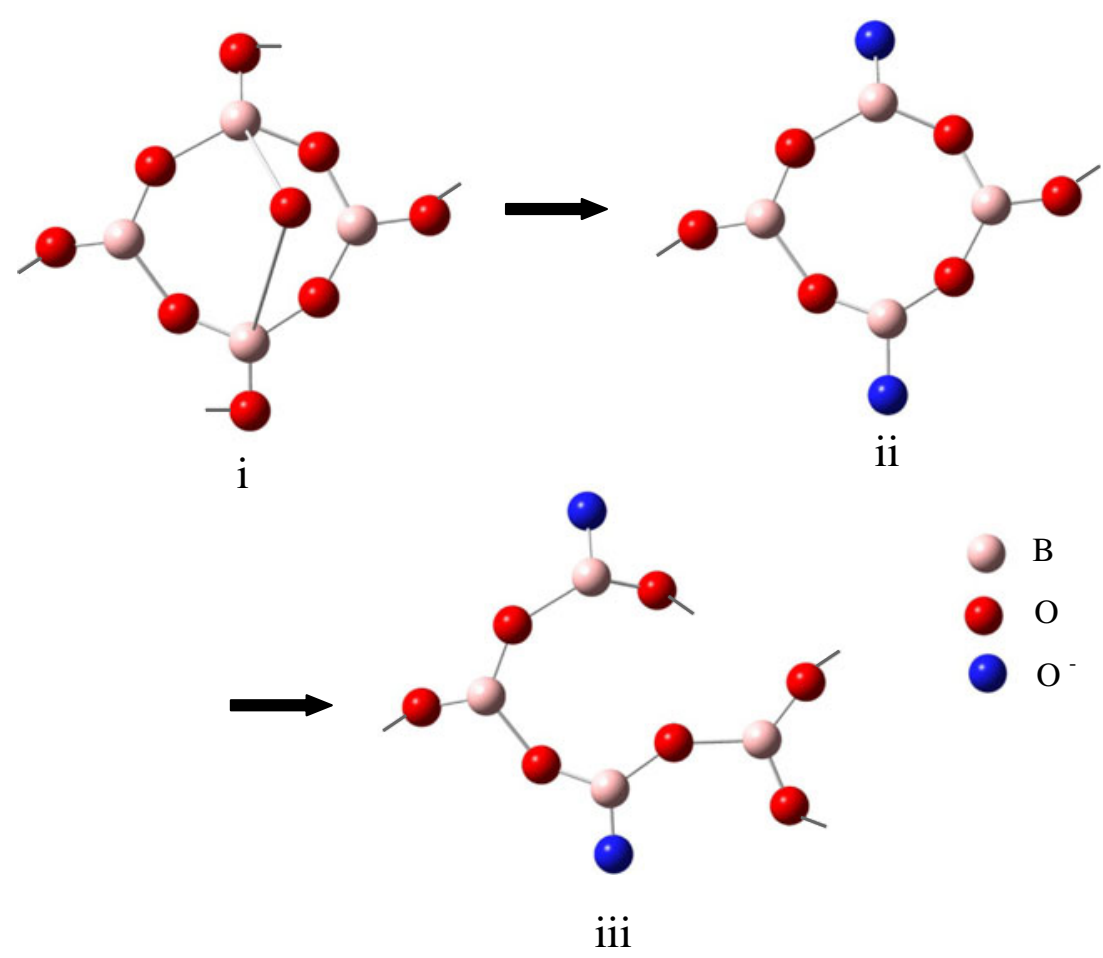

Scheme 3. Opening of tight diborate unit into a linear chain without any change in its chemistry. 
consistent with the structural model. $\left[\mathrm{BiO}_{3 / 2}\right]$ network integrates and permeates through diborate matrix according to the model and each bismuth atom tries to make coordination to three more oxygens as its wont from $\left[\mathrm{B}_{4} \mathrm{O}_{7}\right]^{2-}$ units. Since each $\left[\mathrm{B}_{4} \mathrm{O}_{7}\right]^{2-}$ unit possesses only seven oxygens, it can provide seven non-bonded coordinations. When there is $30 \mathrm{~mol} \% \mathrm{Na}_{2} \mathrm{~B}_{4} \mathrm{O}_{7}$ in the glass, there will be $0.3 \times 7$ moles of oxygen coordinations which are available and this is just enough for 0.7 moles of bismuth atoms which require $0.7 \times$ 3 moles of oxygen coordinations. Thus a coordination saturation is reached at this composition. Theoretically all bismuth atoms have three non-bonded coordinations to oxygen atoms of $\left[\mathrm{B}_{4} \mathrm{O}_{7}\right]^{2-}$ groups. Beyond this limit, bismuth will have to be content with lower coordinations to oxygen. This can cause formation of larger structural voids and it affects in a positive way migration of $\mathrm{Na}^{+}$ions to new positions (This is the second stage in the model proposed). The reversal of compositional dependence of conductivity as observed in figure 3 is thus well understood. It is also possible as noted elsewhere (Veeranna Gowda et al 2007) diborate units open up creating isolated $\mathrm{B}_{4}$ units which revert to $\mathrm{B}_{2}^{-}$or $\left[\mathrm{BO}_{2 / 2} \mathrm{O}\right]^{-}$ units (see scheme 3 ) and in that case $\mathrm{BO}-\mathrm{NBO}$ switching occurs with greater facility (it is, however, not evident if a small decrease of activation barrier results as a consequence).

\subsection{A.C. conductivity}

Frequency dependent conductivities are shown in figure 6 as $\log \sigma$ vs $\log f$ plots for several temperatures up to $250^{\circ} \mathrm{C}$. Variations are very typical of glasses and at all temperatures we have found frequency independent plateau which extends to higher and higher frequencies at higher and higher temperatures. The variations follow Almond-West behaviour (Almond et al 1982, 1983, 1984),

$$
\sigma(\omega)=\sigma_{\mathrm{o}}+A \omega^{s},
$$

where $s$ is the exponent which generally is such that $0<$ $s \leq 1$. The fits to the equation are shown as thin lines in figure 6b. The dispersion is remarkably small (goodness of fit).

In a similar analysis of a.c. conductivities of sodium ion containing (NASICON type) phosphate glasses (Sobha and Rao 1995), we observed better fits using expressions of the type

$$
\sigma(\omega)=\sigma_{\mathrm{o}}+A \omega^{\mathrm{s}_{1}}+B \omega^{\mathrm{s}_{2}} .
$$

We have examined the quality of fits obtained with such threeterm equation and with two sets of $s$ values: (i) $s_{1}=0.5, s_{2}$ $=1.0$ and (ii) with both $s_{1}$ and $s_{2}$ set as freely floated parameters. As examples, we have shown such fits in figures 7 (b) and (c). We note using the first choice of $s_{1}=0.5, s_{2}=1 \cdot 0$, the fit is only marginally improved and the contribution of the 2nd term is rather small (see inset legends in figure 7). In the case of freely floated $s_{1}$ and $s_{2}, s_{1}$ turns out to be very close
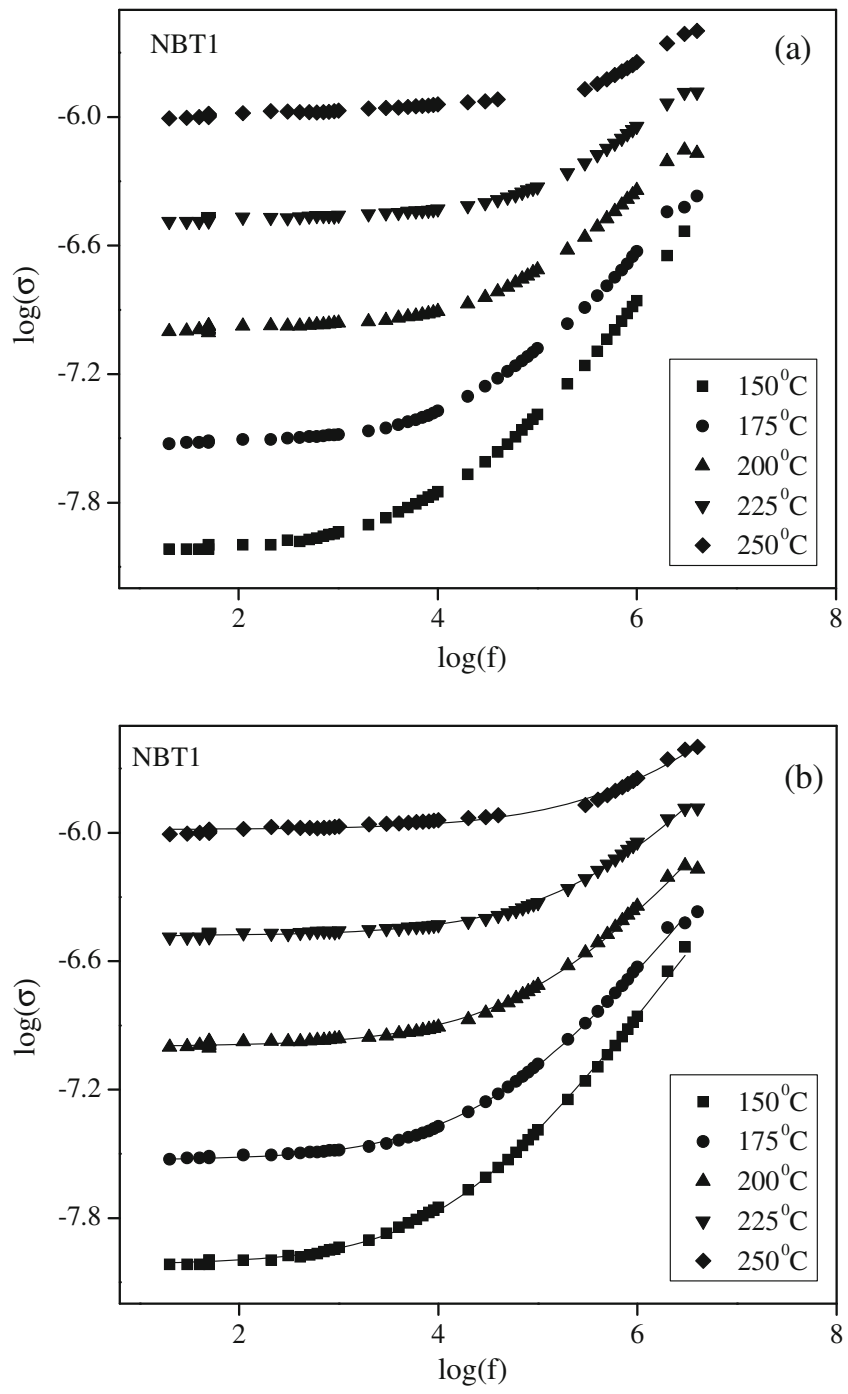

Figure 6. (a) Variation of $\log (\sigma)$ vs $\log (f)$ for NBT1 glass at different temperatures and (b) typical a.c. conductivity plots fitted to power law equation for NBT1 glass.

to the $s$ value obtained from the two term equation. Here also the third term of three term power law is significantly smaller than the second term. The notable features of the power law analysis are therefore (i) the two-term power law seems to be quite adequate in fitting the a.c. conductivity and (ii) values of $s$ (see figure 8) for all the glasses shown at all temperatures seem to fall in a narrow range and are remarkably constant. The exponent characterizing the frequency dependence of conductivity is essentially independent of both composition and temperature.

We note here that traditional models based on cation hopping among equivalent sites should have given rise to composition and temperature dependent $s$ values, because the concentration and distribution of equivalent sites would be affected by the composition (presence of $\mathrm{Pb}, \mathrm{Te}$ or $\mathrm{Bi}$ ) and the hopping parameters would be affected by temperature and in turn affected the exponents. But in the approach 

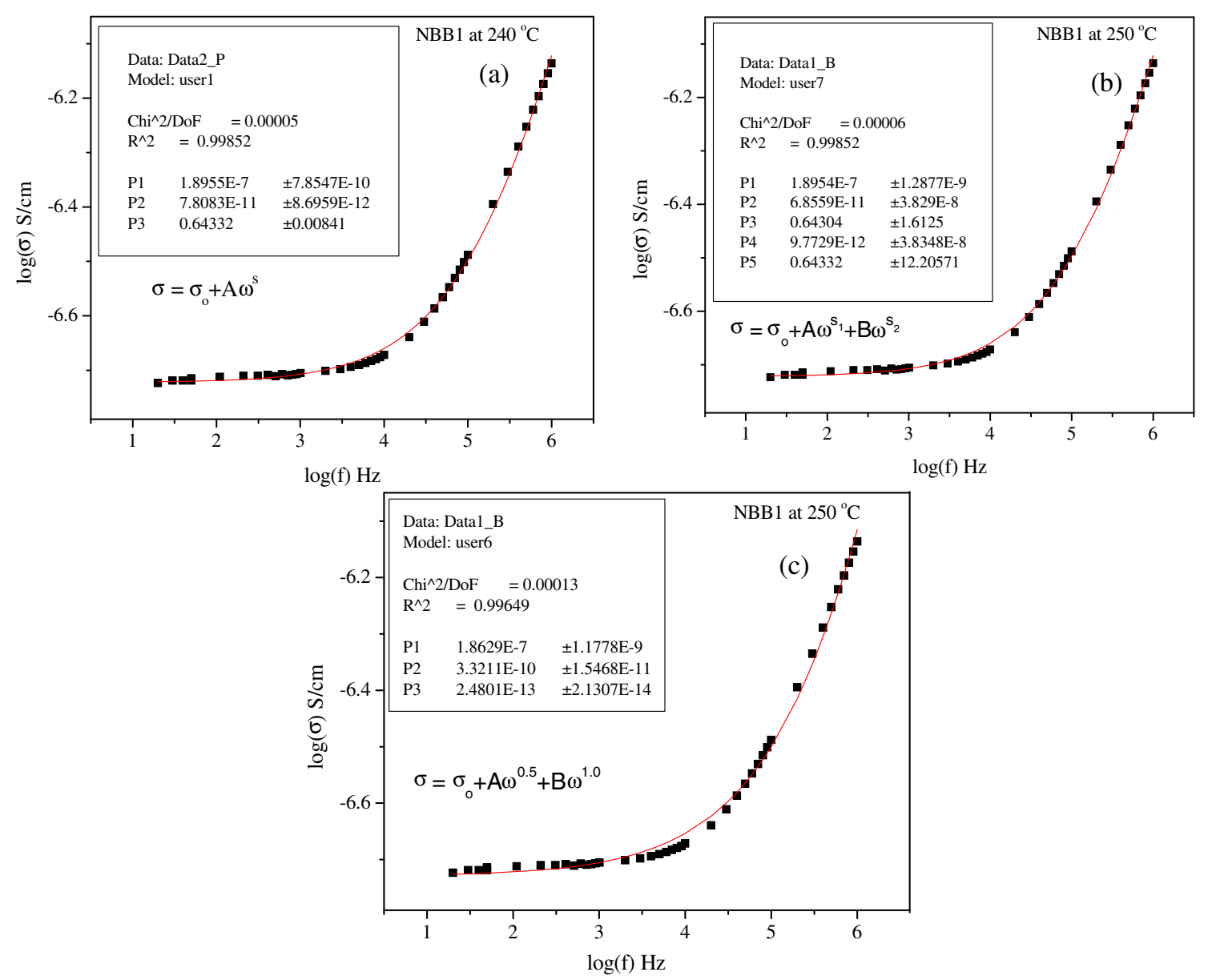

Figure 7. (a) Single power law fit, (b) double power law fit with variable exponents and (c) double power law fit with fixed exponents.

proposed here the charge transfer is controlled by NBO-BO switching of the borate network only. The other aspects of the structure viz. presence of lead, tellurium and bismuth may only secondarily affect the NBO-BO switching.

Therefore, we would not expect the frequency dependence of this process to be much affected by either composition or temperature. The observation of an essentially constant value of ' $s$ ' is thus readily justified. This is also consistent with the observed collapse in reduced $\log \left(\sigma / \sigma_{\mathrm{o}}\right)$ vs $\log \left(f / f_{\mathrm{o}}\right)$ plots.

The above observations are strengthened by the analysis of the a.c. conductivity using moduli representation. The variation of moduli is shown as $M^{\prime \prime}$ vs $\log f$ in figure 9. Magnitudes of $M^{\prime \prime}{ }_{\max }$ are rather similar in each class of glasses (NBP/NBT/NBB). In reduced plot of $M^{\prime \prime} / M_{\max }^{\prime \prime}$ vs $\log \left(f / f_{\mathrm{o}}\right)$, collapse of the plots is extraordinary in the sense that collapse occurs even up to very high frequencies (see figure 10). The calculated value of $\beta$ from the graph of FWHM vs $\beta$ values for all the glasses are shown in figure 11 . Here again the constancy of $\beta$ and its independence on composition and temperature points towards the existence of a common transport mechanism. As earlier we attribute this feature to NBO-BO switching mechanism which is the primary process in charge transport.

\subsection{Further aspects of $\mathrm{NBO}-\mathrm{BO}$ switching for ion transport in glasses}

It is a long held view that ionic conductivity in glasses is through the transport of ions with low electrical charge through the action of jumping between equivalent positions in a manner very similar to the process that occurs in crystalline solids like alkali halides. In crystals presence of well defined defects like vacancies and interstitials exist and jumping of alkali ions is easily visualized. In glasses presence of a vacancy as charge and mass singularity is generally (and perhaps unjustifiably) not well accepted. Even then it is assumed particularly in oxide glasses that the charge transporting cations are positioned closest to NBOs and they jump to similar positions; neighbourhood of another NBO which is assumed to be an equivalent position. In the process it is supposed to move through the crowded environment by mecha- 


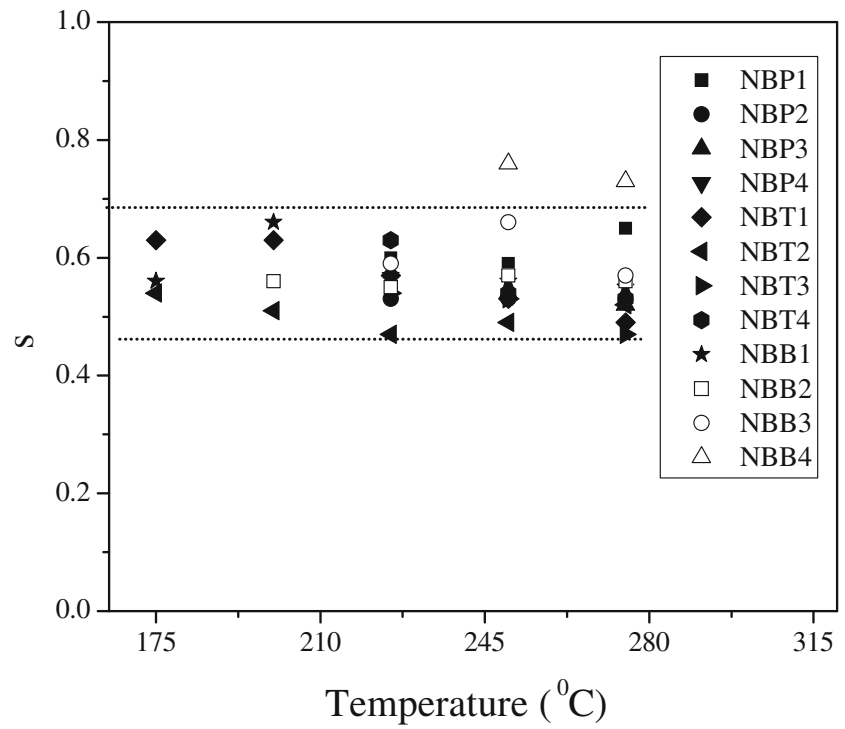

Figure 8. Variation of power law exponent, $s$, with temperature.

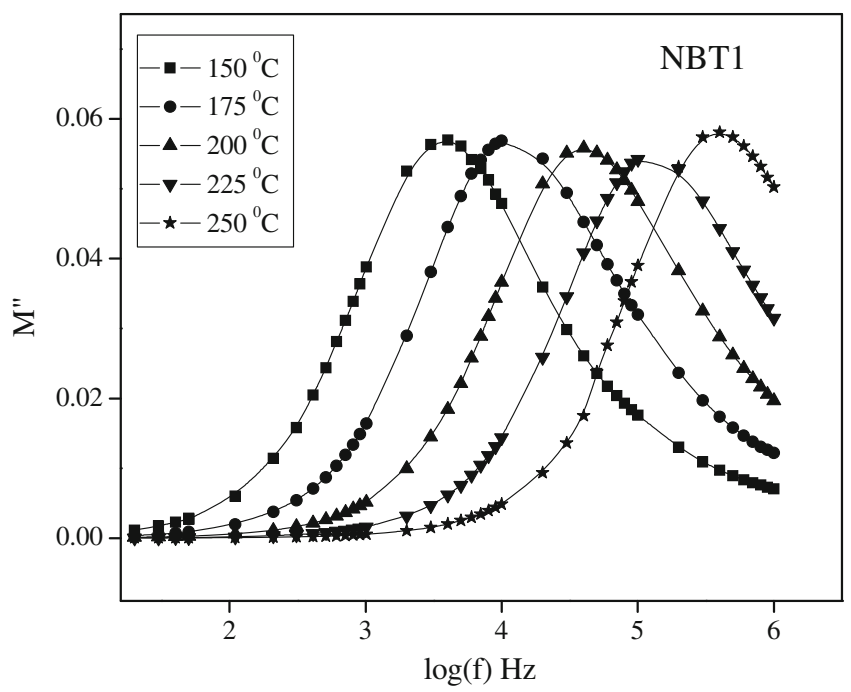

Figure 9. Variation of $M^{\prime \prime}$ with $\log (f)$ at different temperatures.

nically pushing aside oxygens which results in a mechanical barrier component of the activation energy. The unstated implication is that NBOs are positionally fixed at the point of glass transition and they do not move, at least on the time scale of the observed ion transport (see Dyre et al 2009 for a thoughtful discussion of problems in understanding ion conductivity in glasses which unfortunately does not address this problem). This to our knowledge is not clearly established experimentally. It is easily seen that when BO-NBO switching takes place, there is clearly only a charge transport while when a cation like $\mathrm{Na}^{+}$moves, there is both an electrical and mass transport. We recognize that NBO-BO switching causes a local destabilization because the cation which was situated close to NBO now finds itself a neighbour to a BO and will be induced to move onto the neighbourhood of a

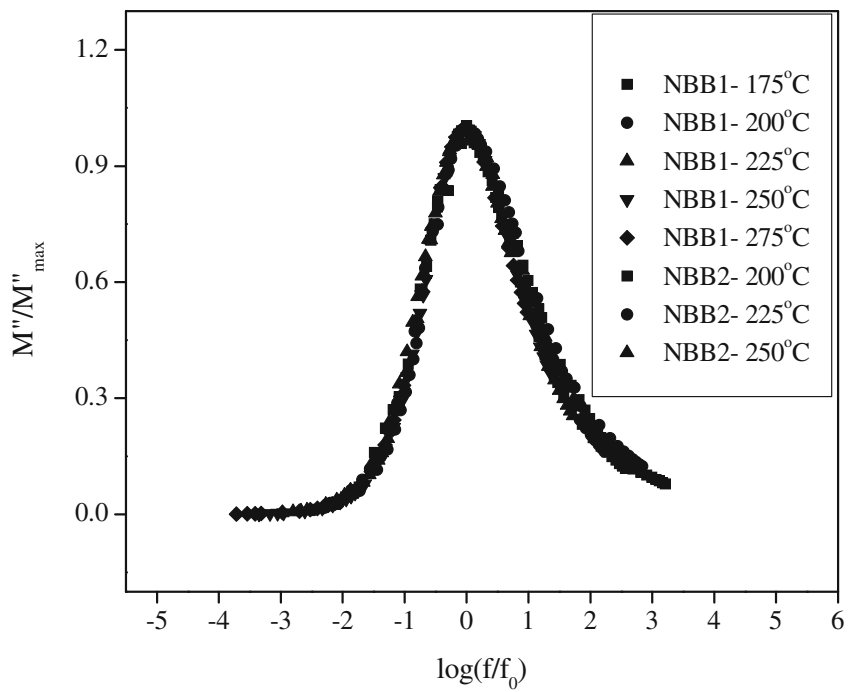

Figure 10. Reduced plot of dielectric modulus at different compositions and temperatures.

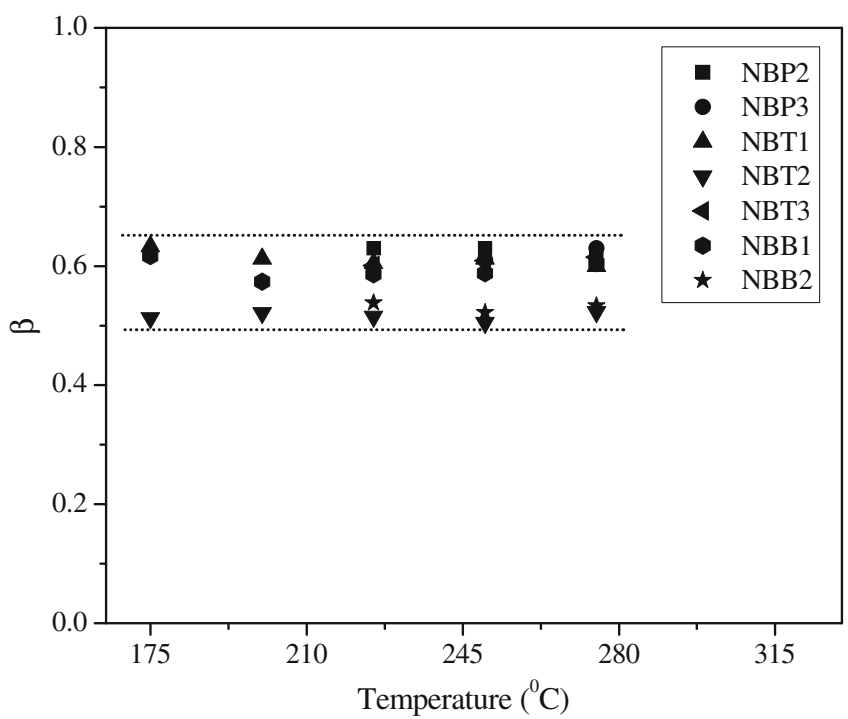

Figure 11. Variation of $\beta$ with temperature.

nearby NBO. Thus the cation transport is a forced consequence and not a primary independent cause in ionic conductivity phenomena in the proposed model. Can NBO-BO switching really occur and what would be its effects on the widely accepted conductivity expression?

We propose that NBO-BO reactions occur in a facile manner via what looks like $S_{\mathrm{n}} 2$ reaction and a bond breaking occurs post creation of a over coordinated activated state (see scheme 1). The intermediate step involves a five coordinated silicon which uses $2 s^{1} 2 p^{3} 3 s^{1}$ hybridized state as a intermediate state. It looks like the principal energy expense in creating the activated state is the difference in energies of five coordinated silicon ( $\mathrm{Si}: 2 s^{2} 2 p^{2} 3 s^{1}$ hybridized, $s p^{3} s^{1}$ ) and four coordinated silicon ( $\mathrm{Si}: 2 s^{2} 2 p^{2}$ hybridized, $s p^{3}$ ). 
These energies are very much in the range of an electronvolt (encouraging results have been obtained from on going density functional theory (DFT) calculations which will be published later). In other oxide glasses such as in borates, four-coordination of boron can be easily visualized such as switching between tetrahedral and trigonal borons.

Therefore, we feel that in ion transport NBOs are not fixed structured entities on the time scales of transport property measurements but are the main participants. Alkali ion motions are a necessary consequence and generally characterized by lower energy barriers. There are notable merits of this approach to ion transport. Since BO-NBO switching is primary to this analysis, activation barriers may simply be in a small range in any particular class of glasses as indeed is the general observation. Power law exponents must be similarly reflecting only the effect of a.c. field on BO-NBO switching.

Ion transport in glasses (Stevels 1957; Mazurin 1965) uses the expression

$$
\sigma_{\mathrm{dc}}=\sigma_{0} \exp \left(-\frac{E_{\mathrm{dc}}}{k T}\right)
$$

which is derived from defect model of transport in crystalline materials. $\sigma_{\mathrm{o}}$ represents the pre-exponential factor

$$
\sigma_{0}=\frac{n(z e)^{2} \lambda^{2} v_{0}}{6 k T}
$$

In the above expression, $\lambda$ represents the distance of jump of the charge transporting ion and of the order of one or two unit lengths in the lattice (few $\AA$ ). $Z e$ is the charge (and is equal to unity in appropriate units) for alkali ions, $k$ the Boltzmann constant and $T$ the absolute temperature. $v_{\mathrm{o}}$ refers to attempt frequency made by the ion before it hops onto another similar site. It is generally equated to the cage vibrational frequency of the alkali ions (around $220 \mathrm{~cm}^{-1}$ or $6.6 \times 10^{12} \mathrm{~Hz}$ ) (Muthupari and Rao 1994; Exarhos and Risen 1972). $\sigma_{0}$ can also be obtained by extrapolation of experimental $\log \sigma$ vs $1 / T$ plots. The $\sigma_{\mathrm{o}}$ value so obtained can be used in the above expression to estimate $v_{0}$ which for the case of NBB1 is found to be $\sim 225 \mathrm{~cm}^{-1}$.

If the primary transport is the $\mathrm{BO}-\mathrm{NBO}$ switching this equation still be valid as we have argued elsewhere (Harish Bhat et al 2004a,b) because Ze still remains the same $(+1$, it is one positive unit for alkali ions). $n$ the concentration of the transporting positive (alkali ions) and is exactly equal to the NBO concentration. $v_{\mathrm{o}}$ now stands to represent the attempt frequency made by NBO in establishing the activated state. This is most likely the low frequency twisting, bending or scissoring frequency. It may fall in the region of a few hundred $\mathrm{cm}^{-1}$ and will leave the value of $\sigma_{\mathrm{o}}$ unaffected except by a numerical factor which at any rate no greater than two or three. Therefore, d.c. conductivities measured and analysed using the above expression in the literature for oxide glasses are completely consistent with the NBO-BO switching model.

One should expect bending-scissoring or twisting $\mathrm{MO}^{-}$ frequencies ( $\mathrm{M}$ being silicon, boron, phosphorous etc) to be generally broad bands in oxide glasses lying in the far infrared region. Further whether it is $\equiv \mathrm{P}-\mathrm{O}^{-}$or $\frac{\searrow}{2} \mathrm{Si}-\mathrm{O}^{-}$ even $-\frac{\mathrm{B}}{-}-\mathrm{O}^{-}$, it would still be similar in value because $-\mathrm{O}^{-}$ is connected to a covalently bonded matrix of high mass and the frequency being $\sqrt{\frac{f}{\mu}} \approx \sqrt{\frac{f}{m_{\mathrm{O}^{-}}}}$. The $f$ values (which scale as $\sqrt{\frac{1}{r_{m-0}^{3}}}$ ) do not exhibit great spread. Thus the near constancy of $v_{\mathrm{o}}$ is justified.

The response to a.c. field in this model is as follows. Bending or scissoring of NBO mode constitutes a band of non-trivial width but they are all at high frequencies compared to frequencies employed in dielectric measurements $\left(200 \mathrm{~cm}^{-1} \equiv 6 \times 10^{12} \mathrm{~Hz}\right)$. They represent the attempt frequencies made in the process of $\mathrm{BO}-\mathrm{NBO}$ conversion. But each successful $\mathrm{BO}-\mathrm{NBO}$ conversion event is immediately followed by a definite alkali ion jump which causes a new dipole reorientation. We consider this second step which follows the BO-NBO switching as the origin of the observed dielectric response in a.c. measurements.

Analytical expressions of conductivity, whether it refers to data reduction, are universal plots that remain valid even in the BO-NBO switching model of conductivity proposed here. Some of the serious difficulties of interpretation of conductivity behaviour are also resolved by BO-NBO switching model satisfactorily. For example, the cation size independence of the activation barriers observed in silicates (around $20 \%$ concentration of any alkali modifier) activation barriers become equal (Rao and Elliott 1994). Similarly in any region of concentration of alkalis in the mixed alkali glass conductivities two distinct barriers are expected, but the two characteristic alkali barriers are never observed. In the present model there can be but only one barrier irrespective of any numbers or a combination of alkali cations.

Finally we should like to comment on the validity of BNN relation in these glasses. BNN relation requires that $\sigma_{\mathrm{o}}$ be related to $\omega_{\mathrm{p}}$ which is in turn obtained from d.c. and a.c. measurements, respectively. On reflection it appears that the relation is obvious because if $\sigma(\omega)=\sigma_{\mathrm{o}}+A \omega^{\mathrm{s}}$, then it is easily shown that $\omega_{\mathrm{p}}$ occurs at $\sigma(\omega)=2 \sigma_{\mathrm{o}}$ which requires that $\omega_{\mathrm{p}}^{\mathrm{s}}=\sigma_{\mathrm{o}} / A$ which establishes the relation between $\sigma_{\mathrm{o}}$ and $\omega_{\mathrm{p}}$ although not the linear relation obvious in BNN relation. Therefore, it appears that Almond-West relation is more intriguing in its universal validity than BNN relation.

The model proposed here appears as if specific to oxide glasses only (NBO-BO system). It is our premise that it could possibly be generalized and extended to ionically conducting chalcogenide and halide glasses (at least in the temperature regime where halide glasses behave like weak analogs of silicate glasses as well).

\section{Conclusions}

Ionic conductivity in oxide glasses has been analysed using the specific example of $y \mathrm{Na}_{2} \mathrm{~B}_{4} \mathrm{O}_{7} \cdot(1-y) \mathrm{M}_{a} \mathrm{O}_{b}\left(\mathrm{M}_{a} \equiv\right.$ 
$\mathrm{Pb}, \mathrm{Te}, \mathrm{Bi})$ modified diborate glasses for which conductivity measurements have been reported. A new model has been suggested in which the primary event in ion transport is NBO-BO switching. This causes destabilization of cation (alkali ion) which moves to the new position in the neighbourhood of another NBO and this event is characterized by a low barrier. The activation barrier obtained in conductivity measurements represents the barrier for NBO-BO switching. The model, therefore, consistently rationalizes observations like the presence of a single observed activation barrier of very similar magnitude in any given class of glasses. It is also easy to understand why in a.c. conductivity measurements we observe a narrow range of $s$ and $\beta$ values.

The implication of wide validity of BNN relation has been shown to be a consequence of the validity of Almond-West relation.

Observed d.c. and a.c. conductivity variations have been shown to be a consequence of the unique structural features of $\mathrm{PbO} / \mathrm{TeO}_{2} / \mathrm{Bi}_{2} \mathrm{O}_{3}$ containing diborate glasses.

\section{Acknowledgement}

One of the authors (KJR) is thankful to DST for the award of a Ramanna Fellowship (Sr).

\section{References}

Al-Assiri M S, Tashtoush N M, Ragab H S and El-Desoky M M 2008 Phys. Status Solidi (a) 2051540

Almond D P, West A R and Grant R J 1982 Solid State Commun. 44 1277

Almond D P, Duncan G K and West A R 1983 Solid State Ionics 8 159

Almond D P, Hunter C C and West A R 1984 J. Mater. Sci. 19 3236

Altaf M, Chaudhary M A and Siddiqi S A 2001 Mater. Chem. Phys. 7128

Anderson O L and Stuart D A 1954 J. Am. Ceram. Soc. 37573

Angell C A 1990 Chem. Rev. 90523

Angell C A, Pollard L and Strauss W 1965 J. Chem. Phys. 43 2899

Bartholomew R F 1973 J. Non-Cryst. Solids 12321

Barton J L 1966 Verres Refract. 20328

Charles R J 1966 J. Am. Ceram. Soc. 4955

Chen R, Yang R, Durand B, Pradel A and Ribes M 1992 Solid State Ionics 53-56 1194

Chryssikos G D, Liu L, Varsamis C P and Kamitsos E I 1998 J. Non-Cryst. Solids 235-237 761

De Marchi G, Mazzoldi P and Miotello A 1988 J. Non-Cryst. Solids 104211

Doremus R H 1973 Glass science (New York: Wiley)

Dyre J C 1985 Phys. Lett. A108 457

Dyre J C 1986 J. Non-Cryst. Solids 88271

Dyre J C and Schroder T B 2000 Rev. Mod. Phys. 72873

Dyre J C, Maass P, Roling B and Sidebottom D L 2009 Rep. Prog. Phys. 72046501

Elliott S R 1988 Solid State Ionics 27131
Exarhos G J and Risen W M Jr. 1972 Solid State Commun. 11 755

Funke K 1993 Prog. Solid State Chem. 22111

Galy J and Meunier G J 1975 Solid State Chem. 13142

Gandhi P R, Deshpande V K and Singh K 1989 Solid State Ionics 3697

Gao Y and Cramer C 2005 Solid State Ionics 176921

Hakim R M and Uhlmann D R 1971 Phys. Chem. Glasses 12132

Han Y H, Kreidl N J and Day D E 1979 J. Non-Cryst. Solids 30 241

Harish Bhat M, Munia Ganguli and Rao K J 2004a Curr. Sci. 86 676

Harish Bhat M, Kandavel M, Munia Ganguly and Rao K J 2004b Bull. Mater. Sci. 27189

Hughes K and Isard J O 1972 in Physics of electrolytes (ed.) J H Hladik (New York: Academic Press) Vol. 1, p. 351

Hunter C C and Ingram M D 1984 Solid State Ionics 1434

Imre A W, Voss S, Berkemeir F, Mehrer H, Konidakis I and Ingram M D 2006 Solid State Ionics 177963

Isard J O 1959 J. Soc. Glass Technol. $53113 \mathrm{~T}$

Macdonald J R 1983 Impedance spectroscopy emphasizing solid materials and systems (New York: John Wiley and Sons)

Macedo P B, Moynihan C T and Bose R 1972 Phys. Chem. Glasses 13171

Martin S W and Angell C A 1986 J. Non-Cryst. Solids 83185

Mazurin O V 1965 in The structure of glass (New York: Consultants Bureau), Vol. 4, p. 7

Mazurin O V and Borisovskii E S 1957 Sov. Phys. Tech. Phys. 2243

Murugaraj R 2007 J. Mater. Sci. 4210065

Muthupari S and Rao K J 1994 Chem. Phys. Letts 223133

Muthupari S, Lakshmi Raghavan S and Rao K J 1996 J. Phys. Chem. 1004243

Nakajima T 1972 in Annual report, Conference on electric insulation and dielectric phenomena (Washington DC: National Academy of Sciences) p. 168

Namikawa H 1975 J. Non-Cryst. Solids 18173

Pan A and Ghosh A 1999a Phys. Rev. B59 899

Pan A and Ghosh A 1999b Phys. Rev. B60 3224

Rao K J 1987 Rev. Solid State Sci. 155

Rao K J 2002 Structural chemistry of glasses (Elsevier)

Rao K J and Parthasarathy R 1985 Proc. Indian Acad. Sci. (Chem. Sci.) 94201

Rao K J and Elliott S R 1994 Proc. Indian Acad. Sci. (Chem. Sci.) 106903

Rao K J and Harish Bhat M 2001 Phys. Chem. Glasses 42255

Rao K J and Sundeep Kumar 2003 Curr. Sci. 85945

Rao K J, Estournes C, Levasseur A, Shastry M C R and Menetrier M 1993 Philos. Mag. B67 389

Ravaine D, Diard J P and Souquet J L 1975 J. Chem. Soc. Faraday Trans. II 711935

Ravine D 1985 J. Non-Cryst. Solids 73287

Ravine D and Souquet J L 1977 Phys. Chem. Glasses 1827

Ravine D and Souquet J L 1978 in Solid electrolytes (eds) P Hagenmuller and W Van Gool (New York: Academic Press) p. 277

Roling B, Martiny C and Murugavel S 2001 Phys. Rev. Lett. 87 085901

Sidebottom D L, Roling B and Funke K 2001 Phys. Rev. B63 024301

Sobha K C and Rao K J 1995 Solid State Ionics 81145

Souquet J L, Duclot M and Levy M 1998 Solid State Ionics 105 237 
Stevels J M 1957 Handbuch der Physik (Berlin: Springer) Vol. 20, p. 350

Sundeep Kumar and Rao K J 2004a Chem. Phys. Letts 38791

Sundeep Kumar and Rao K J 2004b Solid State Ionics 170191

Sundeep Kumar, Vinatier P, Levasseur A and Rao K J 2004 J. Solid State Chem. 1771723

Terai R 1969 Phys. Chem. Glasses 10147
Tomozawa M 1977 in Treatise on materials science and technology (ed) M Tomozawa (New York: Academic Press) Vol. 12, p. 283

Veeranna Gowda V C and Anavekar R V 2005 Solid State Ionics 1761393

Veeranna Gowda V C, Narayana Reddy C, Radha K C, Anavekar R V, Etourneau J and Rao K J 2007 J. Non-Cryst. Solids 3531150 